\title{
MTA as A Revolution in Endodontics-A Review
}

\author{
Monisha $\mathrm{R}^{1}$, Manish $\mathrm{R}^{2}$ \\ Final year BDS, Saveetha Dental College,India \\ MDS, Department of Conservative Dentistry and Endodontics, Saveetha Dental College,India ${ }^{2}$
}

\begin{abstract}
MTA was developed in the year 1993 as root-end filling material as it possesses the ideal characteristics of orthograde or retrograde filling materials. An ideal material should seal the pathways of communication between root canal system and surrounding tissues, be nontoxic, biocompatible, insoluble in tissue fluids and dimensionally stable. MTA is also been used for pulp capping, pulpotomy, apical barrier formation in teeth with open apexes, repair of root perforations, and root canal filling. The main aim of this article is to review the numerous studies done on various aspects of the material. This article describes the composition, setting reaction, mechanism of action, properties, clinical application and disadvantages of MTA.
\end{abstract}

Key words: Apical barrier, Mineral Trioxide Aggregate, ProRoot MTA,Portland cement, Root end filling

\section{Introduction}

Mineral Trioxide Aggregate (MTA) is a grey coloured dental material used in vital pulp therapy and some endodontic procedures. It was first introduced by Dr.Torabinejad at Loma Linda University for the repair of lateral root perforations in the year 1993 [19].MTA was commercially named as ProRoot MTA in 1998 by Dentsply Tulsa Dental. In 2002,a tooth coloured version of MTA was introduced, commonly referred to as white MTA[4]. MTA was originally developed for the repair of root perforations but is increasingly being used in a wide range of clinical treatments, such as a root-end filling material after root-end resection, as an apical barrier in immature teeth, as a pulp capping agent during vital pulp therapy and pulpotomy in primary and permanent teeth, as a repair material in tooth resorption and as a root canal filling material in the coronal section of horizontally fractured teeth[7]. MTA and Portland cement have the same chemical elements, but Portland cement is not used as they donot possess the property of radiopacity though it has excellent physicochemical properties[8]. MTA was shown to have excellent sealing ability and promoted osteoblast activity. It was less cytotoxic than amalgam, IRM, or super EBA and had an antimicrobial effect[11].

\section{Composition}

ProRoot MTA is a hydraulic calcium-silicate cement derivative of a type I ordinary Portland cement with 4:1 proportions of bismuth oxide added for radiopacity. Portland cement is the active ingredient in white MTA[6]. GMTA basically consists of $22.5 \%$ dicalcium and $53.1 \%$ tricalcium silicate, $21.6 \%$ bismuth oxide and small proportions of tricalcium aluminate and calcium sulphate. Bismuth oxide in MTA provides its radiopacity[9]. The bismuth oxide in MTA has a high relative molecular mass, and an addition of $20 \%$ to PC increased the radiopacity to between 5.34 and $8.26 \mathrm{~mm}$ thickness of $\mathrm{Al}$ which is higher than that recommended by ISO 6876. Bismuth oxide in MTA is not inert. It forms part of the hydrated phase forming a structure composed of calcium silicate-bismuth hydrate and the rest is leached together with calcium hydroxide formed from the hydration of the calcium silicates. The precipitation of calcium hydroxide $(\mathrm{CH})$ in the hydrated paste is reduced in MTA compared to a PC with no addition of bismuth oxide[9].

\section{Setting reactions}

When MTA powder is mixed with water, calcium hydroxide $(\mathrm{CH})$ and calcium silicate hydrate are initially formed and eventually transform into a poorly crystallized and porous solid gel. The ratio of calcium silicate drops because of the formation of a calcium precipitate. The precipitated calcium produces $\mathrm{CH}$, which is the cause of MTA's high alkalinity after hydration. Bismuth afftects $\mathrm{CH}$ precipitation after MTA hydration. Because bismuth oxide dissolves in an acidic environment, it has been suggested that placing MTA in an acidic environment such as inflammatory tissues might result in the release of bismuth oxide. This might decrease MTA's biocompatibility because bismuth oxide does not encourage cell proliferation in cell culture. The amount of sulfur at the surface of set MTA is 3 times higher than the powder forms of MTA, and that this layer protects the cement from further hydration and increased the cement's setting time[1].

Tricalcium silicate sets by the following:

(1) $2 \mathrm{Ca}_{3} \mathrm{OSiO}_{4}+6 \mathrm{H}_{2} \mathrm{O}------>3 \mathrm{CaO} .2 \mathrm{SiO}_{2} \cdot 3 \mathrm{H}_{2} \mathrm{O}+3 \mathrm{Ca}(\mathrm{OH})_{2}$

The setting of dicalcium silicate is given by:

(2) $2 \mathrm{Ca}_{2} \mathrm{SiO}_{4}+4 \mathrm{H}_{2} \mathrm{O}---\rightarrow 3 \mathrm{CaO} .2 \mathrm{SiO}_{2} .3 \mathrm{H}_{2} \mathrm{O}+\mathrm{Ca}(\mathrm{OH})_{2}$ 
The principle products are calcium silicate hydrates and calcium hydroxide. The hydration reactions of the two minor components of Portland cement are influenced by gypsum. In the presence of gypsum and water, tricalcium aluminate forms ettringite $(\mathrm{Ca} 3(\mathrm{AlO} 3) 2(\mathrm{SO} 4) 3.32 \mathrm{H} 2 \mathrm{O})$ according to:

(3) $\mathrm{Ca}_{3}\left(\mathrm{AlO}_{3}\right)_{2}+3 \mathrm{CaSO}_{4}+32 \mathrm{H}_{2} \mathrm{O}---\rightarrow \mathrm{Ca}_{6}\left(\mathrm{AlO}_{3}\right)_{2}\left(\mathrm{SO}_{4}\right)_{3} .32 \mathrm{H}_{2} \mathrm{O}$

After all of the gypsum is consumed, the tricalcium aluminate reacts with ettringite to form monosulphates according to the following:

(4) $\mathrm{Ca}_{6}\left(\mathrm{AlO}_{3}\right)_{2}\left(\mathrm{SO}_{4}\right)_{3} \cdot 32 \mathrm{H}_{2} \mathrm{O}+\mathrm{Ca}_{3}\left(\mathrm{AlO}_{3}\right)_{2}+4 \mathrm{H}_{2} \mathrm{O}-----\rightarrow 3 \mathrm{Ca}_{4}\left(\mathrm{AlO}_{3}\right)_{2}\left(\mathrm{SO}_{4}\right) \cdot 12 \mathrm{H}_{2} \mathrm{O}$

Without gypsum, the tricalcium aluminate might form hexagonal and/or cubic calcium aluminate hydrates $\left(4 \mathrm{CaO} \cdot \mathrm{Al}_{2} \mathrm{O}_{3} \cdot 13 \mathrm{H}_{2} \mathrm{O}\right.$ and $3 \mathrm{CaO} \cdot \mathrm{Al}_{2} \mathrm{O}_{3} \cdot 6 \mathrm{H}_{2} \mathrm{O}$ respectively). These species might also appear intermediate to the formation of ettringite when gypsum is present. Finally, tetracalcium aluminoferrite hydration in the presence of gypsum is as follows:

(5) $2 \mathrm{Ca}_{2} \mathrm{AlFeO}_{5}+\mathrm{CaSO}_{4}+16 \mathrm{H}_{2} \mathrm{O}----\rightarrow \mathrm{Ca}_{4}\left(\mathrm{AlO}_{3} / \mathrm{FeO}_{3}\right) 2\left(\mathrm{SO}_{4}\right) \cdot 12 \mathrm{H}_{2} \mathrm{O}+2 \mathrm{Al} / \mathrm{Fe}(\mathrm{OH})_{3} \quad$ [4]

Hydration of MTA powder results in a colloidal gel that solidifies into a hard structure[16]. Characteristics of the mixture can be influenced by the powder/liquid ratio, method of mixing, pressure used for condensation, type of MTA, the type of storage media, the $\mathrm{pH}$ value of the environment, the type of vehicle, the length of time between mixing and evaluation, thickness of the material and the temperature.

\section{Setting time}

MTA is prepared by mixing its powder with sterile water in a 3:1 powder to liquid ratio. The mean setting time of MTA is $165 \pm 5$ minutes, which is longer than amalgam, super EBA and IRM.MTA setting time and bacterial leakage are adversely influenced when the samples are kept in dry conditions[1].

The setting time of MTA has been quoted by different researchers as 165 minutes,45-140 min for initial and final setting time(Chng et al.2005),40-140 min for initial and final setting time(Islam et al.2006),50 min (Kogan et al.2006),151 $\mathrm{min}$ (Huang et al.2008) and 220-250 $\mathrm{min}$ (Ding et al.2008)[4].

\section{Setting expansion}

material. GMTA shows nearly 4 times greater expansion rate. The reason for this is unclear. The difference in the expansion could be explained by the setting chemistries. Camilleri noted low presence of ettringite and monosulfate phases in the hydrated WMTA. Long slender ettringite crystals are a common member in the setting Portland cement crystal population. As the hydration mechanisms proceeds, these crystals form needle like structures and contribute to the majority of expansion seen in Portland cement. Aluminate and ferrite component of Portland cement form the ettringite crystals. This expansion contributes to the sealing ability of MTA[13].

\section{Mechanism of action}

MTA filled in root canal was found to leach some ions in the following order: calcium, silica, bismuth, iron, aluminum, and magnesium. Optical microscope examination after resection of the root end revealed the presence of white layer between MTA and the root canal walls. This white layer composed of calcium, phosphorus, and oxygen similar to hydroxyapatite. HA can release calcium and phosphorus required for bone metabolism which increases the sealing ability of MTA and promotes the regeneration and remineralisation of hard tissues[1].

\subsection{Solubility}

\section{Physical properties}

Solubility of a solid material is defined as the amount of substance that can be dissolved in a given amount of solvent. The powder to water ratio might influence the amount of solubility. Increasing the water powder ratio increases the MTA solubility and porosity. The addition of bismuth oxide makes MTA as insoluble[1].

\subsection{Compressive strength}

The compressive strength is significantly less than amalgam, IRM and superEBA after 24 hours. However there is no difference in the compressive strength after 3 weeks. When blood gets incorporated into MTA the compressive strength of the material is reduced. At the microstructure level, blood contamination of MTA resulted in a lack of acicular crystals which is the cause for reduced compressive strength[10]. The compressive strength of WMTA is greater than that of GMTA[1].

\subsection{Flexural strength}

The presence of wet cotton pellets for 24hours after placement of MTA increases the flexural strength, while it decreases the flexural strength if WMTA receives moisture from both sides for more than 72 hours[1]. 


\subsection{Push out strength}

The pushout strength of perforation repair materials is an important factor because shortly after perforation repair, tooth function might dislodge the material. MTA has lower push out strength. If MTA is exposed to $\mathrm{pH}$ values higher than 8.4 adverse effect on push out strength resulted[18].

\subsection{Fracture resistance}

The teeth filled with MTA had significantly more resistance to fracture compared with those filled with calcium hydroxide. The resistance to fracture of MTA filled teeth is attributed to the TIMP-2 which inihibit collagen destruction.

\section{Antibacterial effect}

MTA has an antibacterial effect on some facultative bacteria and no effect on any species of strict anaerobes. Some investigation showed that GMTA and WMTA have an antifungal effect. The antifungal effect of MTA might be due to its high $\mathrm{pH}$ or to substances that are released from MTA.

\section{Bioactivity}

A material can be considered bioactive if it evokes a positive response from the host. Bioactive material will be able to induce formation of bond between tissue and the material. An artificial material can bind to living bone by the formation of a bone like apatite layer on its surface in the body environment or by biofunctionalization. It is found that apatite layer forms 5 hours after immersion into a phosphate containing solution and a uniform thickness of the apatite layer is formed in 7 days[6]. Apatite formation might play a role in the mineralization activity of WMTA while having a definite effect on biocompatibility as a layer for tissue attachment[12].

\section{Biocompatibility}

A number of biocompatibility and mutagenicity studies have shown that MTA is a biocompatible material. Nociceptive and antinociceptive effects of WMTA were evaluated in a rat model. WMTA did not irritate nerve tissues and was more effective in relieving orofacial nociceptive pain of formalin injection in comparison to eugenol[15]. Microcirculation was completely restored and new vessels were formed 4 weeks after MTA placement[2].

\section{Clinical application}

MTA is used for root end filling, pulp capping, pulpotomy for primary teeth, apical barrier formation for teeth with necrotic pulps and open apexes, perforation repair, and apexification[3].

\subsection{Root end filling}

In a study where MTA was used as a root end filling material in dogs showed that the material promotes cementum formation in $23 \%$ of specimens $2-5$ weeks after periapical surgery. Cementum deposition is not observed in root end cavities filled with amalgam. Results of MTA studies in dogs and monkeys showed that MTA caused less inflammation than amalgam. More importantly, cementum bridges formed directly over the MTA root-end fillings confirming the tissue friendliness of this material and its potential cementogenic property[14]. Newer varieties of white MTA like MTA Angelus and MTA Bio had the shortest setting time, higher $\mathrm{pH}$ and calcium ion release, and the highest solubility when used as root-end filling material[5].

\subsection{Perforation repair}

Pitt Ford was the first to use the material for furcation perforation repair. The ability of MTA to form cementum in the perforation area is reduced if the perforation area is left untreated for a period of time and becomes contaminated. When comparing super EBA and MTA, the cementum formation is found beneath MTA at 6 months interval. superEBA samples showed mild to severe inflammation around the repair material and no cementum formation during the same time interval.

\subsection{Apical barrier}

Teeth with open apex when treated with MTA showed highest amount of hard tissue formation and the lowest level of inflammation after 90 days.

\subsection{Root canal sealer}

MTA was compared with glass ionomer root canal sealer in dog's teeth. The results showed that MTA consistently induces closure of the main canal foramen by new cementum deposition, with an absence of 
inflammatory cells after 6 months. GIC displayed partial closure of the main canal foramen in some specimens and a mild inflammatory reaction around many roots.

\subsection{Pulp capping}

MTA has been shown to give better results than calcium hydroxide in direct pulp capping of uninflamed animal pulps reported less inflammation and thicker dentine bridge with MTA than calcium hydroxide when used as pulp capping material in human teeth with mechanical pulp exposure. MTA has a similar action to that of calcium hydroxide by conversion of calcium oxide to calcium hydroxide when it reacts with tissue fluids[17].

\section{Drawbacks}

Major disadvantages of MTA include discolouration potential, presence of toxic elements in the material composition, difficult handling characteristics, long setting time, high material cost, an absence of a known solvent for this material and the difficulty of its removal after curing, difficulty in obturation of curved root canals(3).

\section{Conclusion}

MTA is a root-end filling material that meets all the qualities required of an ideal material. It is been widely used for many procedures like pulp capping, pulpotomy, apical barrier formation, and repair of root perforation. MTA produces lesser adverse effects compared to other materials. Though widely used it has many drawbacks like discolouration, high setting time and low push out strength. Further studies should be conducted to overcome the drawbacks.

References

[1] Masoud Parirokh, Mahmoud Torabinejad. Mineral Trioxide Aggregate: A comprehensive literature review-Part I: chemical, physical and antibacterial properties. J of Endodontics, 2010,36(1),16-27.

[2] Masoud Parirokh, Mahmoud Torabinejad. Mineral Trioxide Aggregate: A comprehensive literature review-Part II: leakage and biocompatibility. Journal of Endodontics,2010,36(2),190-202.

[3] Masoud Parirokh, Mahmoud Torabinejad. Mineral Trioxide Aggregate: A comprehensive literature review-Part I: clinical applications, drawbacks and mechanism of action. J of Endodontics,2010,36,

[4] S.C.V. Chedella \& D.W. Berzins. A differential scanning calorimetry study of the setting reaction of MTA. International Endodontic Journal, 2010,43,509-518.

[5] Rodrigo Ricci Vivan,Ronald Ordinola Zapata, Marcia A Zeferino. Evaluation of the physical and chemical properties of two commercial and three experimental root-end filling materials. OOO 2010,110(2)250-256.

[6] M.G. Gandolfi, P. Taddei, A. Tinti \& C. Prati. Apatite forming ability (bioactivity) of ProRoot MTA. International Endodontic Journal, 2010,43,917-929.

[7] M.H. Nekoofar, K. Oloomi, M.S. Sheykhrezae, R.Tabor, D.F.Stone. An evaluation of the effect of blood and human serum on the surface microhardness and surface microstructure of MTA. International Endodontic Journal,2010,43,849-857.

[8] E.G.Zeferino, C.E.S.Bueno, L.M.Oyama \& D.A.Riberio. Ex vivo assessment of genotoxicity and cytotoxicity in murine fibroblasts exposed to white MTA or white Portland cement with 15\% bismuth oxide. International Endodontic Journal, 2010,43,843-848.

[9] J.Camilleri. evaluation of the physical properties of an endodontic Portland cement incorporating alternative radiopacifiers used as root-end filling material. International Endodontic Journal,2010,43,231-240.

[10] M.H.Nekoofar,D.F.Stone,P.M.H.Dummer. the effect of blood contamination on the compressive strength and surface microstructure of MTA. International Endodontic Journal,2010,43,782-791.

[11] Amany E. Badr. Marginal adaptation and cytotoxicity of bone cement compared with amalgam and MTA as root-end filling materials. Journal of Endod 2010,36(6),1056-1060.

[12] Farzad Danesh, Zahra Tootian, Jahanfar Jahanbani. Biocompatibility and mineralization activity of fresh or set WMTA, biomimetic carbonated apatite and synthetic hydroxyapatite. Journal of Endodontic, 2010,36(6),1036-1040.

[13] Michael Hawley, Terry D. Webb,Gary G.Goodell. effect of varying water-to-powder -ratios on the setting expansion of white and gray mineral trioxide aggregate. Journal of Endodontic2010,36(8),1377-1379.

[14] Seung-Ho Baek, Woo Cheol Lee, Frank C. Setzer and Syngcuk. Periapical bone regeneration after endodontic microsurgery with three different root-end filling materials:amalgam,super EBA and MTA. Journal of Endodontic2010,36(8),1323-1325.

[15] F. Abbasipour,A.Rastqar,H.Bakhtiar . the nociceptive and anti nociceptive effects of WMTA. International Endodontic Journal2009,42,794-801.

[16] J.Camilleri. Characterization of hydration products of MTA. International Endodontic Journal2008,41,408-417.

[17] D.Tuna,A.Olmez. clinical long-term evaluation of MTA as a direct pulp capping material in primary teeth, International Endodontic Journal, 2008,41,273-278.

[18] Mohammad Ali Saghiri, Noushin Shokouhinejad, Mehrdad Lotfi. Push out bond strength of MTA in the presence of alkaline pH. Journal of Endodontics,2010,36(11)1856-1859.

[19] Effect of MTA and Portland cements on inflammatory cells.Journal of Endodontic, 2010,36(5)899-903. 